\title{
Analysis on Damaging Mechanism of Sand-Mud Interbedded Strata Type Perilous Rock
}

\section{Ping Dong ( 1205651926@qq.com )}

Chongqing Institute of Geology and Mineral Resources https://orcid.org/0000-0002-6866-6963

\section{Yuntao Zhou}

Institute of Prospecting Technology,Chinese Academy of Geological Sciences

\section{Dan Liang}

Chongqing Institute of Geology and Mineral Resources

\section{Research Article}

Keywords: Geotechnical engineering, Damage mechanical mechanism, Criteria, Slip-shear, Dump-fall, Base, Perilous rock

Posted Date: April 19th, 2021

DOI: https://doi.org/10.21203/rs.3.rs-382364/v1

License: @ (i) This work is licensed under a Creative Commons Attribution 4.0 International License. Read Full License 


\title{
Analysis on Damaging Mechanism of Sand-mud Interbedded Strata
}

\section{Type Perilous Rock}

\author{
Ping Dong ${ }^{1}$, Yuntao Zhou ${ }^{2}$, Dan Liang ${ }^{1}$ \\ (1.Chongqing Institute of Geology and Mineral Resources, Chongqing, 401120, PR China; 2.Institute of \\ Prospecting Technology, Chinese Academy of Geological Sciences, Chengdu 611734, Sichuan, PR China)
}

\begin{abstract}
Aiming at the sand-mud interbedded strata type perilous rock, this paper comprehensively analyzes the reason of formation of perilous rock and its structural characteristics, builds the physical and mechanical mode of the sand-mud interbedded strata type perilous rock, puts forward the base retreat mechanism that the mudstone's softening, compression and deformation induce the tension damage of thin layer sandstone, explains slip-shear damage mode and dump-fall damage mode of perilous rock, and proposes mechanical criteria of two damage modes. According to the results of case analysis, the base retreat of perilous rock in Leijiagou conforms to the mechanical mechanisms of the tension and damage of thin layer sandstone induced by the softening, compression and deformation. Under current situations, there will be no slip-shear damage or dump-fall damage for the Leijiagou Perilous Rock. According to preliminary projections, the Leijiagou Perilous Rock will lose its stability after 15.2 years, with the damage mode being dump-fall damage and the critical depth of cavity being $4.1 \mathrm{~m}$.
\end{abstract}

Keywords: Geotechnical engineering; Damage mechanical mechanism; Criteria; Slip-shear; Dump-fall; Base; Perilous rock

\section{Introduction}

Red beds refer to the clastic rocks of lacustrine facies, fluvialite facies, alternate lake and pool facies or diluvium facies and equal alluvial facies since Mesozoic (i.e. Triassic, Jurassic, Cretaceous and Cenozoic Paleogene). They are widely distributed in areas such as the Southwest China, South China, Southeast China and Northwest China ${ }^{[1]}$. As the typical stratum developed by collapse of perilous rock, red beds mostly appear in the form of the interbedded layers of giant thick of sandstone, siltstone, and mudstone ${ }^{[2]}$. Influenced by the differential weathering of sandstone and mudstone, the mudstone strongly weathered in the red bed area mostly forms the rock cavity, unweathered mudstone becomes base, while the sandstone body covered above mostly becomes perilous rock and is the typical mudstone base type perilous rock in red layer region ${ }^{[3]}$. In recent years, we have discovered sand-mud interbedded strata type perilous rock in the red layer region. Unlike mudstone base type perilous rock, this kind of perilous rock is covered with a thin layer of sandstone, and its thickness is nearly the same as that of mudstone. According to the field observation, because of the thin sandstone, the combined action of the softening effect of the below-lying mudstone and the weight of the overlying perilous rock is often preferentially destroyed, which causes the accelerated development of rock cavity. Compared with the mudstone base type perilous rock, it is more dangerous and is the focus of research in red layer areas.

The destruction of perilous rock is influenced by many factors. According to Igwe $\mathrm{O}$ et al. ${ }^{[4]}$, the main factors that cause the destruction of perilous rock are steep slope, brae structure, drainage pattern, broken rocks, and the increase of pore water pressure. Tang Hongmei, Chen Hongkai et al. found the ringing effect of the perilous rock destruction, and thought that excitation is the incentive to induce the damage of mother rock ${ }^{[5-7]}$. As pointed out by Chen Wei, Tang Hongmei et 
al., the differential weathering of sand mudstone is the direct cause of the destruction of perilous rock in red layer areas ${ }^{[8-9]}$. At present, the research on perilous rock mainly centers on the extended rupture of main control structure. For example, Collins B D and Luethi $\mathrm{R}^{[10,11]}$ both put forward the temperature difference effect mechanism of fracture extension and damage of perilous rock. Furthermore, Matasci B et al. ${ }^{[12,13]}$ proposed the mechanical destruction mechanism of the plane slide of perilous rock, wedge landslide and falling. Meanwhile, He Siming et al. ${ }^{[14]}$ put forward the destruction mechanism of the fracture shear of perilous rock under the effect of the earthquake. Chen Hongkai et al. ${ }^{[15]}$ explained the mutation mechanism of the destruction of Wangxia perilous rock. Zheng Anxing et al. ${ }^{[16]}$ raised the limited element simulation method of deformation and expansion failure of main control structure of perilous rock.

Aiming at sand-mud interbedded strata type perilous rock, we put forward the relevant physical mode, analyze the mechanical mechanism of sand-mud interbedded strata retreat, discuss the destruction mode of perilous rock, put forward the perilous rock damage criteria, and apply the proposed damage mechanism to the perilous rock in Liejiagou, and predict the mode and time of perilous rock damage. Besides, our research findings play a critical and supporting role in increasing the development of perilous rock in red rock area and the knowledge for its damage mechanism.

\section{Mechanical Analysis of Retreat Mechanism of Sand-mudstone Strata}

\subsection{Physical Mode of Sand-mudstone Strata Type Perilous rock}

For the perilous rock containing sand-mudstone strata, we comprehensively analyze the origin and structural characteristics of perilous rock, and put forward the physical mode of sand-mudstone strata type perilous rock (Fig.1). This model simplifies the perilous rock as euclidean body. The height of perilous rock is $H$, the sickness is $B$, and the rear edge is unloading tensional fissure. Since sandstone is brittle elastomer material, the crack is usually a through-going state after cracking and the angle is close to $90^{\circ}$. The bottom of the perilous rock is sand-mudstone strata, which is composed of thin sandstone and thin mudstone with the width of $l$. The thin sandstone has a thickness of $h_{s}$, and thin mudstone has a thickness of $h_{n}$. Besides, the relationship between $h_{s}, h_{n}$ and the height of perilous rock strata $H$ is as follows

$H / h_{s} \geq 10, \quad H / h_{n} \geq 10, \quad 1 / 3 \leq h_{s} / h_{n} \leq 3$

Where, $H$ refers to the height of perilous rock, $h_{s}$ refers to the thickness of thin sandstone, and $h_{n}$ refers to the thickness of thin mudstone.

Under long-term weathering and fracturing of overlying perilous rock, sand-mudstone mostly forms cavity, whose initial depth is $a_{0}\left(a_{0}=B-l\right)$. The development of the cavity provides necessary condition for the instability and damage for the perilous rock ${ }^{[3,17]}$. 


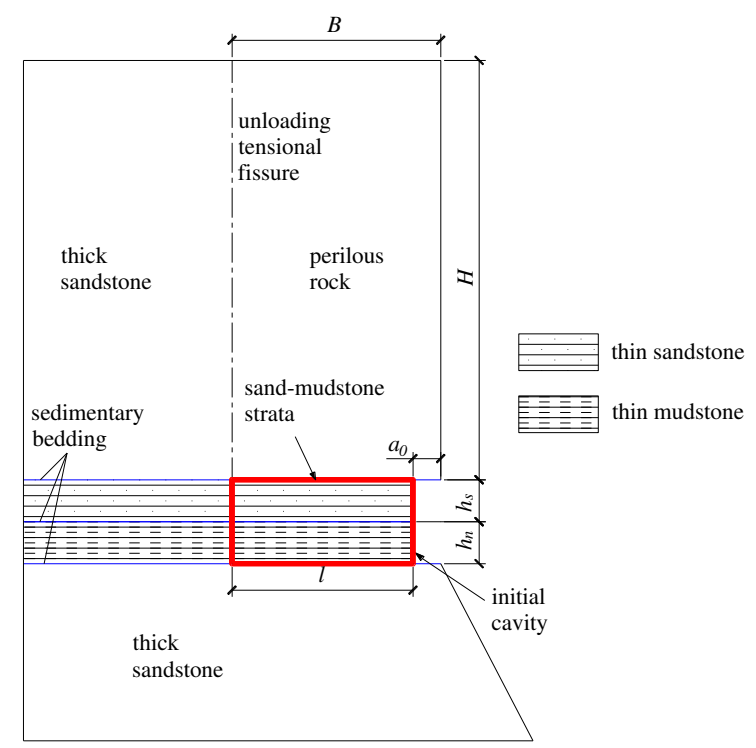

Fig.1 Physical model of unstable-rock with sand-mudstone interbed foundation

\subsection{Mechanical Analysis of Mudstone Softening and Base Retreat}

In the natural state, mudstone has a tight structure and high strength. In the saturated state, the porosity of mudstone continues to increase, the connection among particles becomes loose, and the structure becomes porous as the water-filling time increases. At the same time, it is accompanied by the reduction of macroscopic mechanical indicators such as elastic model, shear strength and compressive strength ${ }^{[18-20]}$. As shown in Fig.2, under rainfall conditions, rain water flows into the sedimentary bedding surface along the through-going tension fissure of the rear edge of the perilous rock, and then seeps out through the bedding surface channel. Under the condition of long-term raining, the rain water contacts the mudstone and thin mudstone forms soften area within a certain range. The length of the soften area is $l_{0}$, and the thickness is the thickness of thin mudstone $h_{n}$. According to the long-term field observation, rainfall will directly affect the length of mudstone soften area. For heavy rain, the length of soften area is $l_{0} \geqslant 0.8 \mathrm{~m}$. For lightly heavy rain and moderate rain, the length of soften area is $0.5 \leqslant l_{0}<0.8 \mathrm{~m}$. For light rain, the length of soften area is $l_{0}<0.5 \mathrm{~m}$.

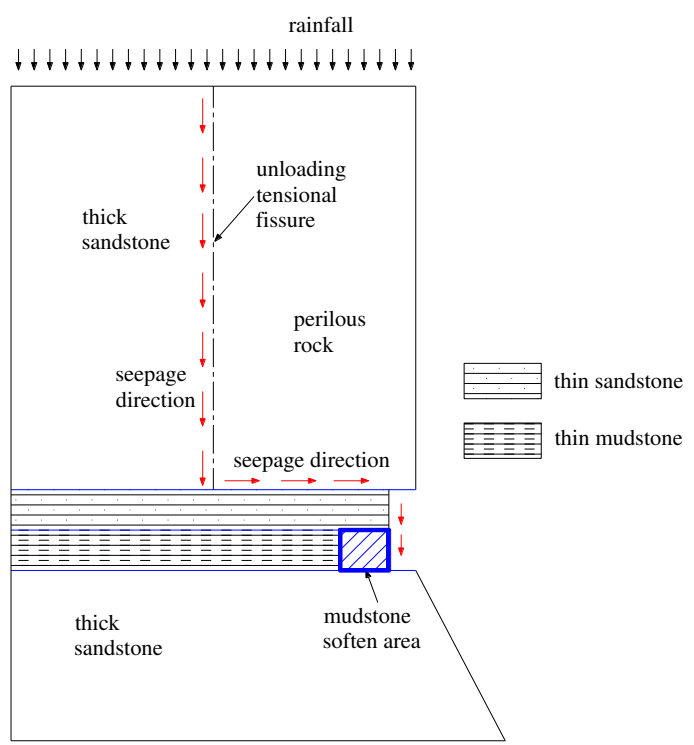

Fig.2 Sketch map for mudstone softening caused by rainfall infiltration 
For the softened mudstone after soaking, its macro mechanical indicators attenuate rapidly with the times of dry-wet cycles, the shear strength parameter decreases exponentially with the times of dry-wet cycles, and the compression modulus decreases exponentially with the times of dry-wet cycles ${ }^{[21]}$. The formula is as follows

$E(n)=E_{n}\left[\alpha e^{m n}+(1-\alpha)\right]$

Where $E_{n}$ refers to the initial compression module; $n$ refers to the number of dry-wet cycles; $\alpha$ and $m$ refer to fitting coefficient, which can be obtained by mudstone dry-wet cycle experiment.

With the decrease of mudstone compression module, the deformation performance of thin mudstone is enhanced, and the deformation increases compared with the upper sandstone. Fig. 3 is the deformation model of thin mudstone. Under the weight of perilous rock, thin sandstone and the deadweight of thin mudstone, thin mudstone will have compression and deformation, which can be calculated by the isotropic homogeneous linear deformation theory as follows

$s=\psi p h_{n} / E(n)$

Where $s$ refers to the deformation of thin mudstone; $p$ refers to the average additional pressure acting on thin mudstone strata; $\psi$ refers to the compression deformation empirical coefficient and is defined by mudstone compression experiment and experience.

Among them, $p$ refers to the average additional pressure produced by the deadweight of perilous rock, thin sandstone and thin mudstone. The formula is

$p=\frac{B H \gamma_{s}}{B-a_{0}}+\gamma_{s} h_{s}+\gamma_{n} h_{n}$

Where $\gamma_{s}$ and $\gamma_{n}$ refer to the sandstone weight and mudstone weight.

By substituting formula (2) and (4) into formula (3), we can get the following formula

$$
s=\frac{\psi h_{n}\left(\frac{B H \gamma_{s}}{B-a_{0}}+\gamma_{s} h_{s}+\gamma_{n} h_{n}\right)}{E_{n}\left[\alpha e^{m n}+1-\alpha\right]}
$$

According to formula (5), we can know that the compression s of thin mudstone gradually increases with the increase of mudstone soaking time. Correspondingly, the deformation of overlying thin sandstone will increase. According to the deformation coordination principle of sedimentary bedding surface between thin sandstone and thin mudstone, the deformation of the center point of thin sandstone should be equal to that of the center point of thin mudstone. As displayed in Fig.5, we simply thin sandstone into cantilever beam subjected to loading only, while the maximum tensile stress of sandstone will appear at the fixed point of the cantilever beam and $A$ point at the outer edge of beam. According to the basic principle of structural mechanism, we ignore the deadweight of the thin sandstone, and the maximum tensile stress $\sigma_{A}$ and the amount of deformation s should satisfy the following formula

$$
\sigma_{A}=\frac{3 E_{s} s h_{s}^{2}}{2 l_{0}^{3}}
$$

Where $\sigma_{A}$ refers to the maximum tensile stress at the upper edge of thin sandstone; $E_{s}$ refers to the elastic module of sandstone; The other physical meanings are the same as those above.

Putting formula (5) into formula (6) and arranging it, then we can get

$$
\sigma_{A}=\frac{3 E_{s} h_{s}^{2} \psi\left(\frac{B H \gamma_{s}}{B-a_{0}}+\gamma_{s} h_{s}+\gamma_{n} h_{n}\right)}{2 l_{0}^{3} E_{n}\left[\alpha e^{m n}+1-\alpha\right]}
$$


According to the maximum tensile stress principle, the condition of tensile damage in thin sandstone is

$\sigma_{A}>\left[\sigma_{t}\right]_{s}$

Where $\left[\sigma_{t}\right]_{\mathrm{s}}$ refers to the tensile strength of sandstone.
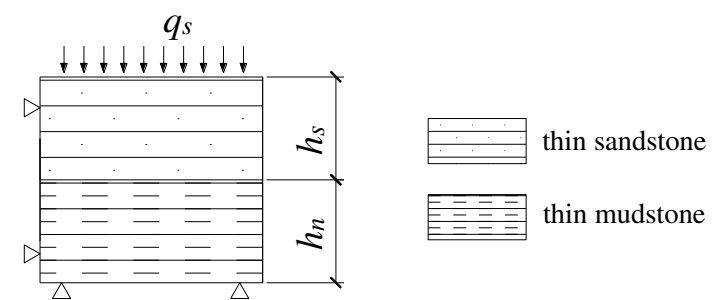

Fig.3 Compressive calculation model for thin mudstone

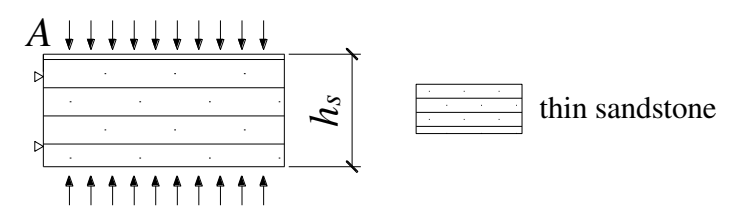

Fig.4 Beam calculation model of thin sandstone

When the mechanical condition of sandstone satisfies the above formula (8), the thin sandstone will undergo tensile failure, the sandstone base in the softened area of mudstone loses the supporting function for the overlying perilous rock, and this part of sand-mudstone also loses the meaning of base. Correspondingly, the cavity below the perilous rock gets deeper. When the softening zone of mudstone with the length of $l_{0}$ disappears into cavity, then rainfall infiltration will continuously soften the subsequent mudstone within a certain depth range to form a new softening area, and induce further destruction of thin layer sandstone to form a new rock cavity. With such a long-term cycle, rock cavity will gradually deepen until perilous rock loses stability and is damaged.

\section{Failure mode and mechanical criterion of Perilous rock}

For the sand-mud interbedded strata type perilous rock, the main factor to control the instability of perilous rock is the mechanical parameter after the mudstone softens and the cavity depth of base recedes. After the mudstone softens, shear strength parameter are significantly reduced, and the shear strength of the base is reduced, so that it is difficult to support the overlying perilous rock pressure and the damage of sand-rock interbedded strata occurs. Meanwhile, the damage model is slip-shear (Fig.5). The softening of mudstone causes the damage of thin sand-stone, the rock cavity continues to deepen, and the empty surface of the lower part of the perilous rock increases. Under the action of gravity, the perilous rock will turn and damage, and the damage model is dump-falling(Fig.6).

\subsection{Mechanical Criteria of Slip-shear Damage}

As displayed in Fig.5, if the shearing of perilous rock damage satisfies Mohr-Coulomb principle and the shearing damage surface goes through sand-mudstone interbedded strata, then the shear force formed by fracture water pressure $q_{u}$ and gravity of perilous rock $W$ is

$T=\left(q_{r} \sin \theta+q_{u} \cos \theta\right) \frac{h_{s}+h_{n}}{\sin \theta}$ 
$q_{r}=\frac{B H \gamma_{s}}{B-l-a_{0}}$

$q_{u}=\frac{\gamma_{w} h_{w}^{2} \sin \theta}{2\left(h_{s}+h_{n}\right)}$

Where $T$ refers to the shear force on the shear surface; $q_{r}$ refers to the average pressure of the upper perilous rock; $l$ refers to the increased depth of rock cavity, $l=l_{0}+l_{1}+\cdots \cdots+l_{\mathrm{n}}$, and the subscript $n$ refers to the number of times that the base is damaged by soaking and softening; $q_{u}$ refers to the average fissure water pressure; $\theta$ refers to the shear rupture angle; $\gamma_{w}$ refers to the weight of water; $h_{w}$ refers to the water column height of tension fissure at the back edge of perilous rock, which can be calculated according to Design Code for Geological Hazard Prevention and Control of Chongqing Local Standards (DB50/5029-2004) ${ }^{[22]}$. The other physical meanings are the same as those above.

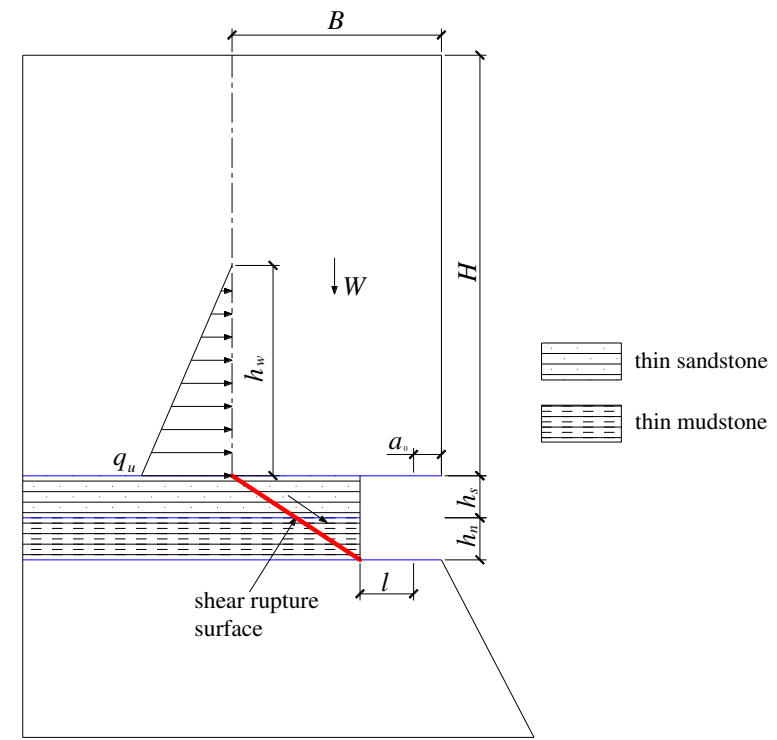

Fig.5 Failure mode of slip-shear

The shear force on the shear surface should be the sum of the resistant forces of thin sandstone and thin mudstone, it is

$T_{f}=\frac{\left(q_{r} \cos \theta-q_{u} \sin \theta\right)\left(h_{s} \tan \varphi_{s}+h_{n} \tan \varphi_{n}\right)+\left(c_{s} h_{s}+c_{n} h_{n}\right)}{\sin \theta}$

Where $T_{f}$ refers to the resisting shear force on the shear plane; $\varphi_{s}$ and $c_{s}$ refer to the internal fraction angle and cohesion force of the thin sandstone respectively; $\varphi_{n}$ and $c_{n}$ refer to the internal fraction angle and cohesion force of the mudstone respectively, using the strength parameter after soaking.

When the slip-shear damage model occurs, the mechanical criterion of sand-mud interbedded strata type perilous rock is

$T-T_{f}=0$

Putting formula (9) and formula (12) in the formula (13) and arranging it, then we can get

$\left(q_{r} \sin \theta-q_{u} \cos \theta\right)\left(h_{s}+h_{n}\right)-\left(q_{r} \cos \theta-q_{u} \sin \theta\right)\left(h_{s} \tan \varphi_{s}+h_{n} \tan \varphi_{n}\right)-\left(c_{s} h_{s}+c_{n} h_{n}\right)=0$

\subsection{Dump-fall Damage Mechanical Criterion}

As shown in Fig.6, it is assumed that the depth of the rock cavity increases by $l$, the perilous 
rock rotates and damages along point $O$. We can analyze it by two situations. When the gravity point of the perilous rock is at the left side of the rotating point, it is $B / 2 \geqslant a_{0}+l$. The gravity force of the perilous rock provides anti-overturning torque, and fracture water pressure provides overturning torque, which is

$M_{q}=\frac{\gamma_{w} h_{w}^{3}}{6}$

Gravity force and tensile strength of sedimentary bedding surface between thin sandstone and upper perilous rock sandstone provides the anti-overturning torque of perilous rock, which is

$M_{f}=B H \gamma_{s}\left(\frac{B}{2}-a_{0}-l\right)+\frac{\left(B-l-a_{0}\right)^{2}\left[\sigma_{t}\right]_{c}}{2}$

When the gravity point of the perilous rock lies at the right side of the rotating point, that is $B / 2<a_{0}+1$, and the gravity force of the perilous rock provides overturning torque, then the overturning torque is

$M_{q}=B H \gamma_{s}\left(a_{0}+l-\frac{B}{2}\right)+\frac{\gamma_{w} h_{w}^{3}}{6}$

Tensile strength of sedimentary bedding surface between thin sandstone and upper perilous rock sandstone provides the anti-overturning torque of perilous rock, which is

$M_{f}=\frac{\left(B-l-a_{0}\right)^{2}\left[\sigma_{t}\right]_{c}}{2}$

Where $M_{q}$ and $M_{f}$ are overturning torque and anti-overturning torque of perilous rock respectively; $\left[\sigma_{t}\right]_{c}$ refers to the tensile strength of sedimentary bedding surface between thin sandstone and upper perilous rock sandstone.

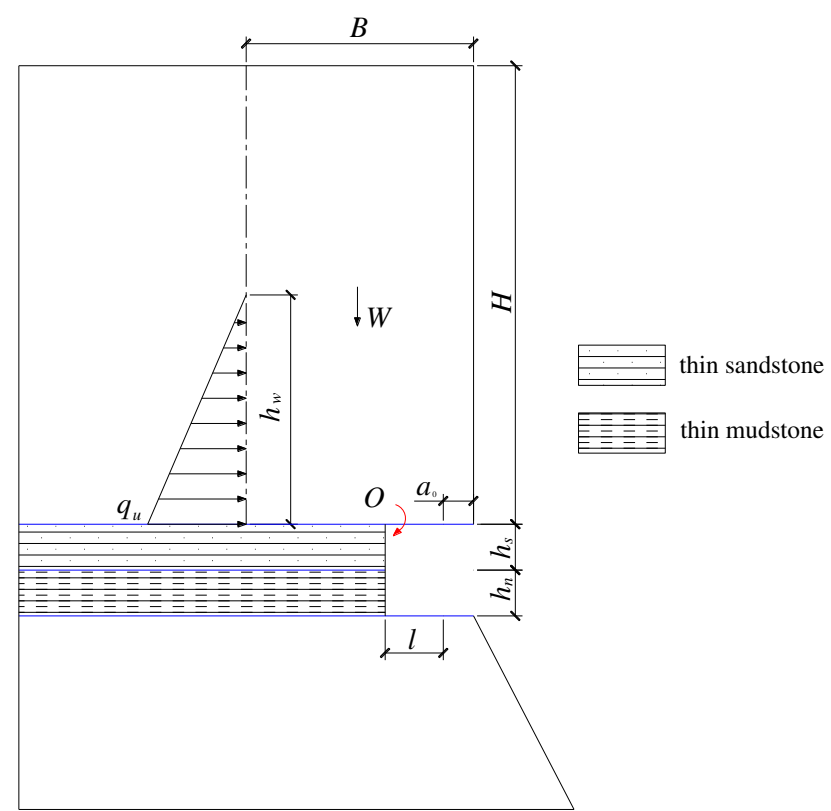

Fig.6 Failure mode of toppling-fall

When the dump-fall damage model happens, the mechanical criterion of sand-mud interbedded strata type perilous rock is

$$
M_{q}-M_{f}=0
$$




\section{Case Analysis}

\subsection{Overview of Leijiagou Perilous Rock in Bazhong City}

Leijiagou Perilous Rock is situated in the second group of Hangu Village, Mingyang Town, Enyang District, Bazhong City, Sichuan Province (E: $106^{\circ} 37^{\prime} 1.07^{\prime \prime}$, N: $31^{\circ} 46^{\prime} 34.85^{\prime \prime}$ ). This area is located in the middle and low hills and is 350-600 $\mathrm{m}$ above sea level. The perilous rock is located at the top of the slope. The top elevation is $390 \mathrm{~m}$, the bottom is $350 \mathrm{~m}$, and the height difference is about $40 \mathrm{~m}$. Apart from that, the slope is $210^{\circ}$, and the upper part of the slope is about $85^{\circ}$. The perilous rock area mainly develops the Lower Cretaceous Bailong $\left(\mathrm{K}_{1} \mathrm{~b}\right)$ formation giant thick layer yellowish brown sandstone, and includes thin sandstone as well as thin mudstone. The earth is near the horizontal level and occurs at $195^{\circ} \angle 3^{\circ}$. The fracture surface of unloading joint is developed in the posterior, which is completely through-going, and the fracture surface is $178^{\circ} \angle 87^{\circ}$. The fracture is easy to be filled with water, and the main source of water in the area is rainfall.

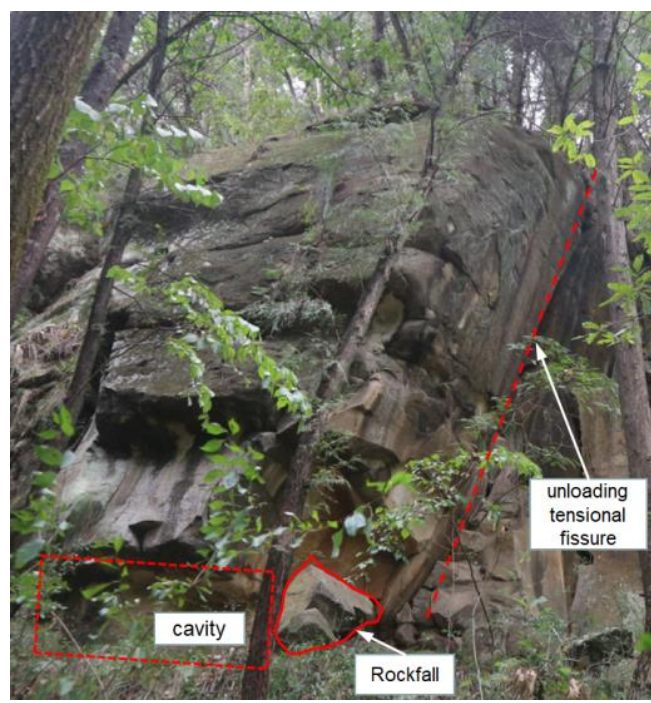

Fig.7 Full view of Leijiagou Perilous Rock

As shown in Fig.7 and Fig.8, the perilous rock is located in the middle and upper part of the slope with a height of $10.5 \mathrm{~m}$, a thickness of $8.7 \mathrm{~m}$, and a width of $7.0 \mathrm{~m}$. The monomer volume of perilous rock is about $639.0 \mathrm{~m}^{3}$ and it is a middle-sized perilous rock. Perilous rock has thin sand-mudstone strata on its foot, and the thin sandstone has the thickness of about $0.8 \mathrm{~m}$, and the mudstone has a thickness of about $1.0 \mathrm{~m}$. Meanwhile, traces of water immersion on the surface of mudstone can be seen obviously. The first partial destruction of the perilous rock occurred on July 1,2015 , in which stones with a diameter of about $1.3 \mathrm{~m}$ fell to the gentle area. The horizontal caving distance was about $25 \mathrm{~m}$, and only $6.0 \mathrm{~m}$ from the residential houses. This accident seriously threatened the life safety of 26 persons in 6 families and the threatened assets are over 100 million Yuan. In July 2018, under the influence of strong rainfall, this perilous rock was destroyed twice, and the two fallen rocks are both located at the bottom of the cliff with a diameter of $2.5 \mathrm{~m}$ and $0.8 \mathrm{~m}$. Luckily, they didn't roll to the foot of the slope which was a residential point. According to initial judgment, this perilous rock has a high risk under the deadweight and the fracture water pressure. 


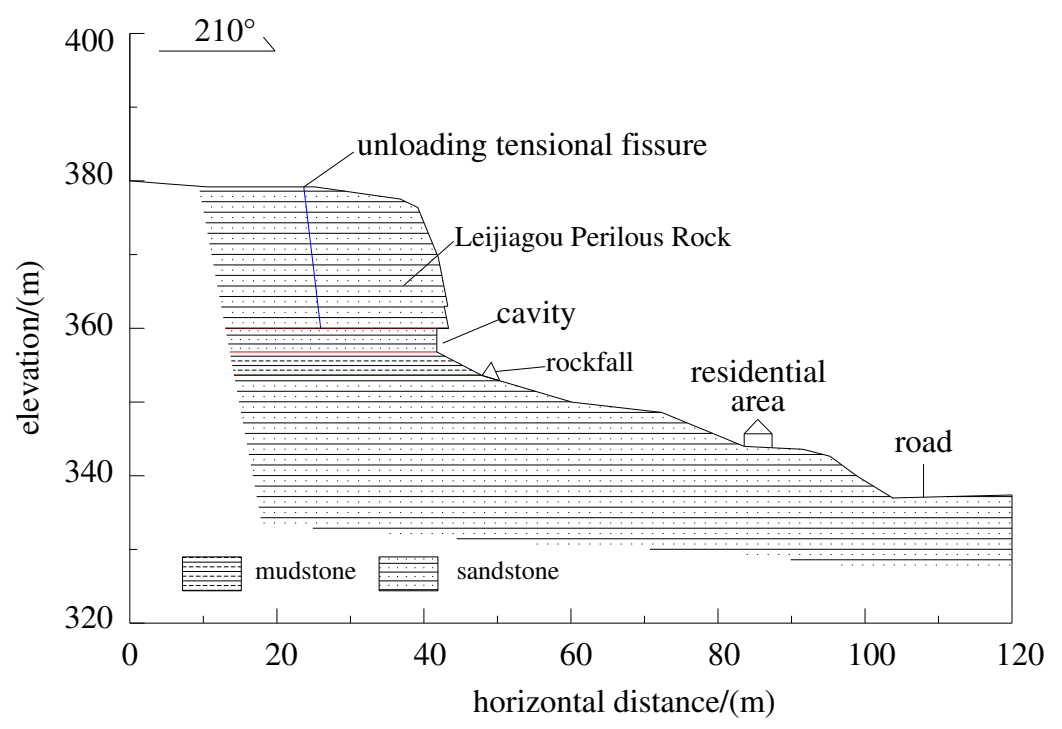

Fig.8 Engineering geologic profile of Leijiagou Perilous Rock

\subsection{Analysis on the Retreat of Leijiagou Perilous Rock}

As shown in Fig.9, the base of Leijiagou Perilous Rock is formed by $0.8 \mathrm{~m}$ thin sandstone and $1.0 \mathrm{~m}$ thin mudstone. The tension fracture at the back edge of the perilous rock is completely connected. Under the condition of rainfall, the rain soaks the perilous rock base, making the mudstone softening. According to the speculation from May to July in 2018, only if it rained for over 12 hours successively, could mudstone in the base reach the biggest infiltration depth. Considering the worst situation, according to the data of heavy rain in Bazhong City from July 2015 to July 2018, the dry-wet cycling times of mudstone is $n=45$ times, and the soaking depth is $l_{0}=0.8 \mathrm{~m}$. Using the fitting coefficient obtained from the dry-wet cycle test of mudstone compression modulus in the literature ${ }^{[21]}, \alpha=0.77, m=-1.71$, the formula of mudstone compression modulus with dry-wet cycle times is

$$
E(n)=6500.0 \times\left(0.77 e^{-1.71 n}+0.23\right)
$$

The compression modulus of mudstone cycling 45 times is $1514.5 \mathrm{MPa}$. According to the physical and mechanics parameters in formula (4) and Tab.1, we can get $p=344.6 \mathrm{kPa}$, the average additional force generated by the deadweight of perilous rock, thin sandstone, and thin mudstone. Furthermore, we put the mudstone compression modulus 1514.5MPa after dry-wet cycle and the average additional force $344.6 \mathrm{kPa}$ into the formula (3), and calculate the compression deformation of mudstone, which is $0.25 \mathrm{~mm}$. Then, we put the amount of compression deformation $0.25 \mathrm{~mm}$ into formula (6), and get the biggest tension force of thin sandstone $\sigma_{A}=2.13 \mathrm{MPa}>\left[\sigma_{t}\right]_{\mathrm{S}}=1.95 \mathrm{MPa}$. It reveals that thin sandstone has undergone tensile damage, which corresponds to the falling stone with the diameter of $0.8 \mathrm{~m}$ in the base tested in July 2018. That is to say, the retreat of the base is formed when the softening of the mudstone dry-wet cycle induces the deformation of the base, and then it causes the tensile damage of thin sandstone. 


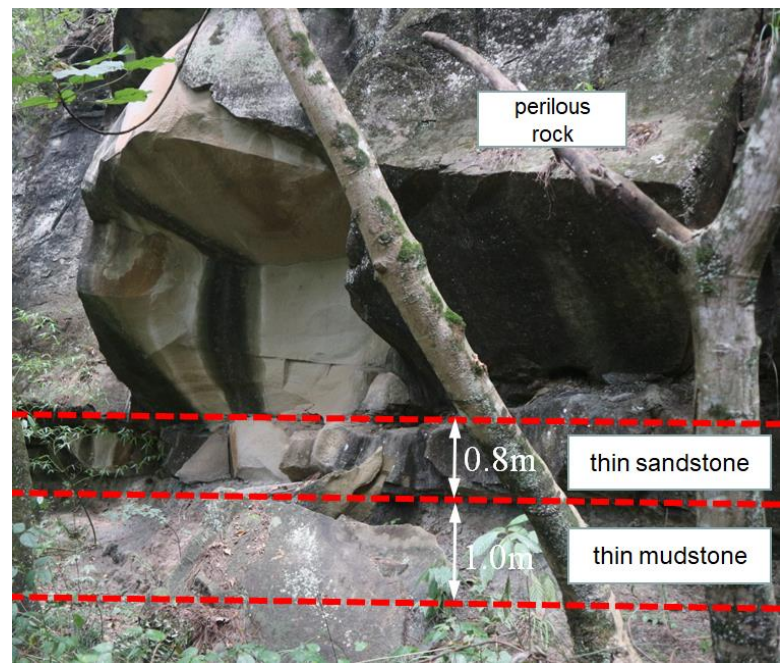

Fig.9 Foundation beds of Leijiagou Perilous Rock

Tab.1 Physical and mechanical param of sandstone and mudstone of Leijiagou Perilous Rock

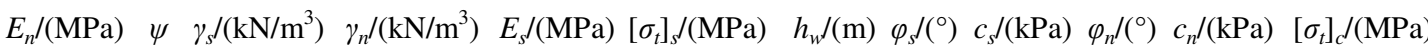

$\begin{array}{llllllllllll}6500.0 & 1.1 & 25.3 & 24.2 & 4532.7 & 1.95 & 5.3 & 33.7 & 924.0 & 25.7 & 112.6 & 0.28\end{array}$

\subsection{Analysis and Discussion of Damage Mechanism of Leijiagou Perilous Rock}

Since Leijiagou Perilous Rock contains bases and cavities, slip-shear damage or dump-falling damage may happen. For slip-shear damage of perilous rock, we can calculate the overlying force $q_{r}=334 \mathrm{kPa}$ by formula (10). The height of fraction water column is $5.3 \mathrm{~m}$, so that we can get average water pressure $q_{u}=19 \mathrm{kPa}$ from formula (11). Besides, we put $334 \mathrm{kPa}$ and $19 \mathrm{kPa}$ into formula (9), and can get the shear forces $(T=736 \mathrm{kN} / \mathrm{m})$ on the shear planes. Then, we put the parameter in table 1 into the formula (12), and get the resistant force on the shear surface $\left(T_{f}=4658 \mathrm{kN} / \mathrm{m}>T=736 \mathrm{kN} / \mathrm{m}\right)$, revealing that slip-shear damage doesn't occur under current situation in Leijigou and the result is the same as that in the field observation.

According to the $B / 2=8.7 / 2=4.35 \mathrm{~m}, a_{0}+l_{0}=1.0+0.8=1.8 \mathrm{~m}$, for dump-fall damage of perilous rock, we use formula (15) and formula (16) for calculation and get the overturning moment $(M q=241 \mathrm{kN} \cdot \mathrm{m})$ as well as the anti-overturning moment $\left(M_{f}=12535 \mathrm{kN} \bullet \mathrm{m}>M q=241 \mathrm{kN} \bullet \mathrm{m}\right)$, which is the same as that in the field observation.

According to the observation data from July 2015 to July 2018, there is a retreat at the base. After the retreat of the base, rainfall continued to soak the base through tension-unloading cracks at the back of perilous rock. Then, the next base retreat occurred. We assume a time lag from July 2015 to July 2018, indicating that 3 years is a period of receding base. If other conditions do not change, after a reverse calculation, Leijiagou Perilous Rock will have slip-shear damage after 6.12 cycles (18.4 years), and corresponding critical depth of rock cavity is $4.9 \mathrm{~m}$. In the same way, after several calculation, the period of dump-fall damage of Leijiagou Perilous Rock is 5.07(15.2 years), and corresponding critical depth is $4.1 \mathrm{~m}$. Taking the smaller value, it can be predicted that the Leijiagou Perilous Rock will be dumped-falling damage in 15.2 years, and the critical depth is $4.1 \mathrm{~m}$. 


\section{Conclusion}

(1)We build the physical model of sand-mudstone interbedded strata type perilous rock, and put forward the base retreat mechanical mechanism that mudstone' s softening, compressing and deformation induce tensile damage of thin sandstone.

(2)We build the mechanical model of sand-mudstone interbedded strata type perilous rock, explain the slip-shear damage model as well as dump-fall damage model of perilous rock, and put forward two mechanical criteria of damage model.

(3) According to the case analysis, the base retreat of Leijiagou Perilous Rock accords with the mechanical mechanism that mudstone's softening, compression and deformation induce tensile damage of thin layer sandstone. In current situation, there is no slip-shear damage or dump-fall damage in Leijiagou Perilous Rock. After initial prediction, we know that Leijiagou Perilous Rock will be unstable after 15.2 years, the damage mode is dump-fall damage, and the corresponding critical depth is $4.1 \mathrm{~m}$.

\section{Acknowledgments}

This work is supported by the National Science Foundation of China (No. 51378521, 51678097), China Geological Survey Project (NO.DD20160278) and Special Research Project of Public Welfare Industry of the Ministry of Land and Resources (NO. 201511051).

\section{References}

[1]PAN Zhi-xin, PENG Hua. Comparative Study on the Global Distribution and Geomorphic Development of Red Beds[J]. Scientia Geographica Sinica, 2015, 35(12):1575-1584.

[2]Guo Yong-chun, XIE Qiang, WEN Jiang-quan Red beds distribution and engineering geological problem in China[J]. Hydrogeology and Engineering Geology, 2007, 34(6):67-71.

[3]ZHOU Yuntao, SHI Shengwei, ZHANG Yong. Stability of unstable rock in nearly-horizontal sandstone-mudstone stratum due to enlarged rock-cell[J]. Journal of Engineering Geology,2017,25(5):1220-1229.

[4]Igwe O, Mode A W, Nnebedum O, et al. The mechanisms and characteristics of a complex rock-debris avalanche at the Nigeria-Cameroon border, West Africa[J]. Geomorphology, 2015, 234:1-10.

[5]TANG Hong-mei, CHEN Hong-kai, WANG Zhi, et al. Experimental study on excitation effect for unstable rock[J]. Chinese Journal of Geotechnical Engineering, 2013, 35(11):2117-2122.

[6]TANG Hong-mei, WANG Zhi, XIAN Xue-fu, et al. Violent-slide rock avalanche and excitation effect of perilous rock[J]. Journal of Chongqing University（Natural Science Edition ）, 2011, 34(10):39-45.

[7]CHEN Hong-kai, ZHANG Rui-gang, TANG Hong-mei, et al. Elastic \& impulsive dynamic param of a ruptured compression-shear perilous rock[J]. Journal of Vibration and Shock, 2012, 31(24):30-33.

[8]TANG Hong-mei, WANG Lin-feng, CHEN Hong-kai, et al. Collapse sequence of perilous rock on cliffs with soft foundation[J]. Chinese Journal of Geotechnical Engineering, 2010, 32(2):205-210.

[9]CHEN Wei, XU Ze-min, LIU Wen-lian. Mechanical model and failure mechanism of unstable cantilevered rock blocks due to differential weathering[J]. Rock and Soil Mechanics, 2015, 36(1):195-204.

[10]Collins B D, Stock G M. Rockfall triggering by cyclic thermal stressing of exfoliation fractures[J]. Nature Geoscience, 2016, 9(5):395-401.

[11]Luethi R, Gruber S, Ravanel L. Modelling transient ground surface temperatures of past rockfall events: towards a better understanding of failure mechanisms in changing periglacial environments[J]. Geografiska Annaler, 2015, 97(4):753-767.

[12]Matasci B, Stock G M, Jaboyedoff M, et al. Assessing rockfall susceptibility in steep and overhanging slopes 
using three-dimensional analysis of failure mechanisms[J]. Landslides, 2017(2):1-20.

[13]Matasci B, Jaboyedoff M, Loye A, et al. Impacts of fracturing patterns on the rockfall susceptibility and erosion rate of stratified limestone[J]. Geomorphology, 2015, 241:83-97.

[14]HE Si-ming, WU Yong, LI Xin-po. Failure mechanism of dangerous rock under seismic tension-shear action[J]. Engineering Mechanics, 2012, 29(4):178-184.

[15]CHEN Hongkai, WANG Shengjuan. Study on failure model of Wangxia perilous rock and its mechanical interpretation[J]. Journal of Chongqing Normal University: Natural Science Edition, 2018,35(1):48-55.

[16]ZHENG An-xing, LUO Xian-qi, SHEN Hui. Numerical simulation and analysis of deformation and failure of jointed rock slopes by extended finite element method[J]. Rock and Soil Mechanics, 2013,34(8):2371-2377.

[17]ZHOU Yun-tao. A method for calculating the stability of unstable rocks on Three Gorges Reservoir by fracture mechanics[J]. Rock and Soil Mechanics, 2016,37(S1):495-499.

[18]REN Song, WEN Yong-jiang, JIANG De-yi, et al. Experimental research on softening in mudstone interlayer[J]. Rock and Soil Mechanics, 2013,34(11):3110-3116.

[19]SHEN Pei-wu, TANG Hui-ming, WANG Ding-jian, et al. Disintegration characteristics of red-bed mudstone of Badong Formation under wet-dry cycles[J]. Rock and Soil Mechanics, 2017, 38(7):1990-1998.

[20]YANG Zhenfeng, MIAO Linchang. Experimental study on silty mudstone strength attenuation and environmental effect[J]. Chinese Journal of Rock Mechanics and Engineering, 2007, 26(12):2576-2582.

[21]Liu xiaoqiang, Zhou shiliang, Shang mingfang, et al. Analysis on mechanical properties of rock based on water-rock interaction[J]. Journal of Chongqing Jiaotong University, 2012, 31(2):268-273.

[22]Chongqing local standard. Design standard of geological disaster prevention and control[S]. DB50/5029-2004:25-27. 
Figures

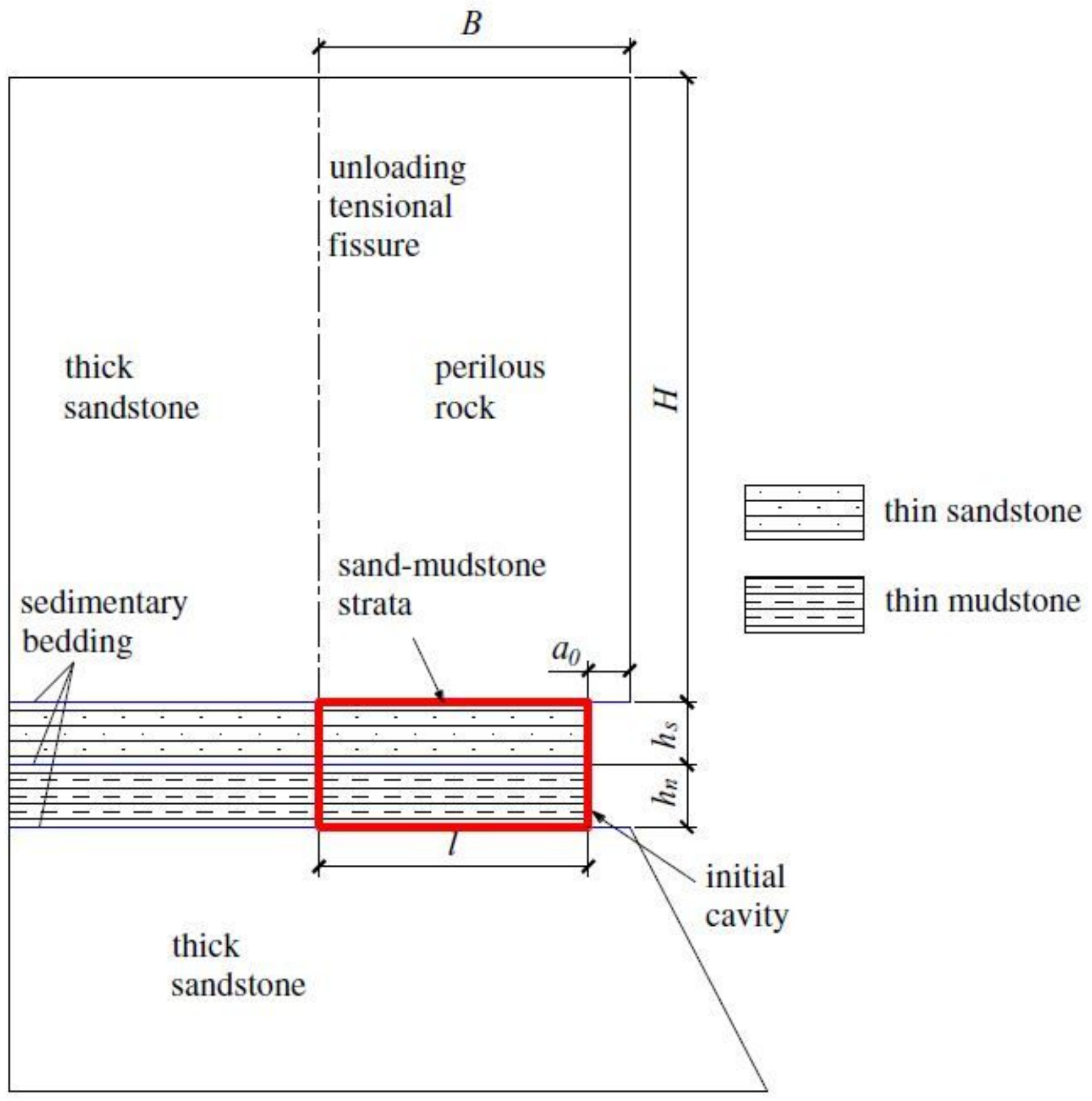

Figure 1

Physical model of unstable-rock with sand-mudstone interbed foundation 


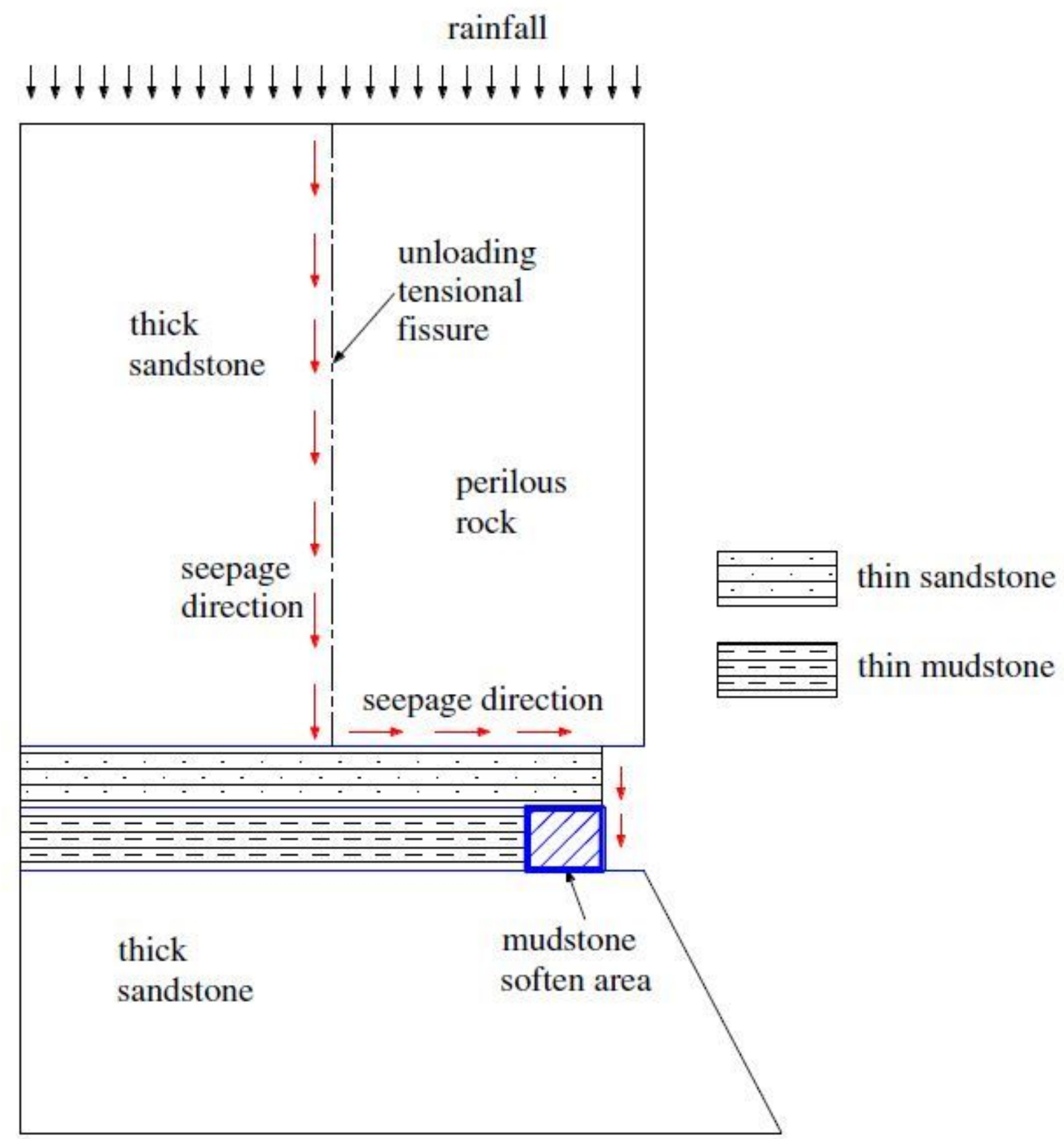

Figure 2

Sketch map for mudstone softening caused by rainfall infiltration 


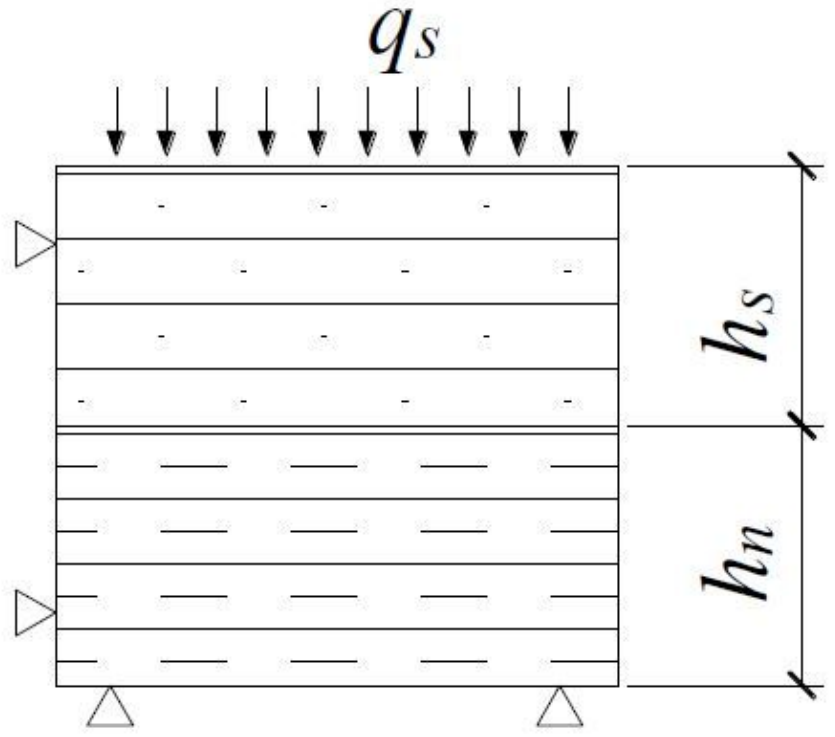

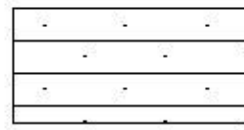

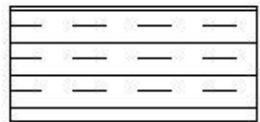

thin mudstone

Figure 3

Compressive calculation model for thin mudstone

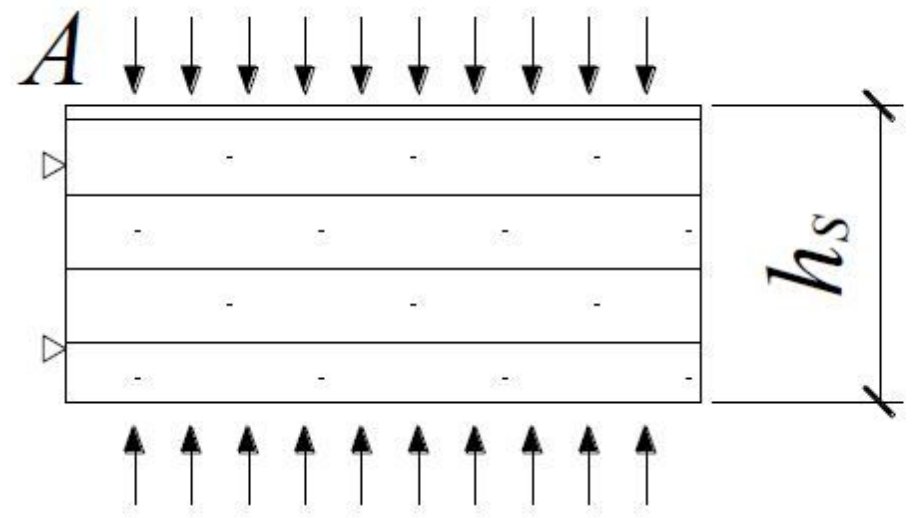

Figure 4

Beam calculation model of thin sandstone 


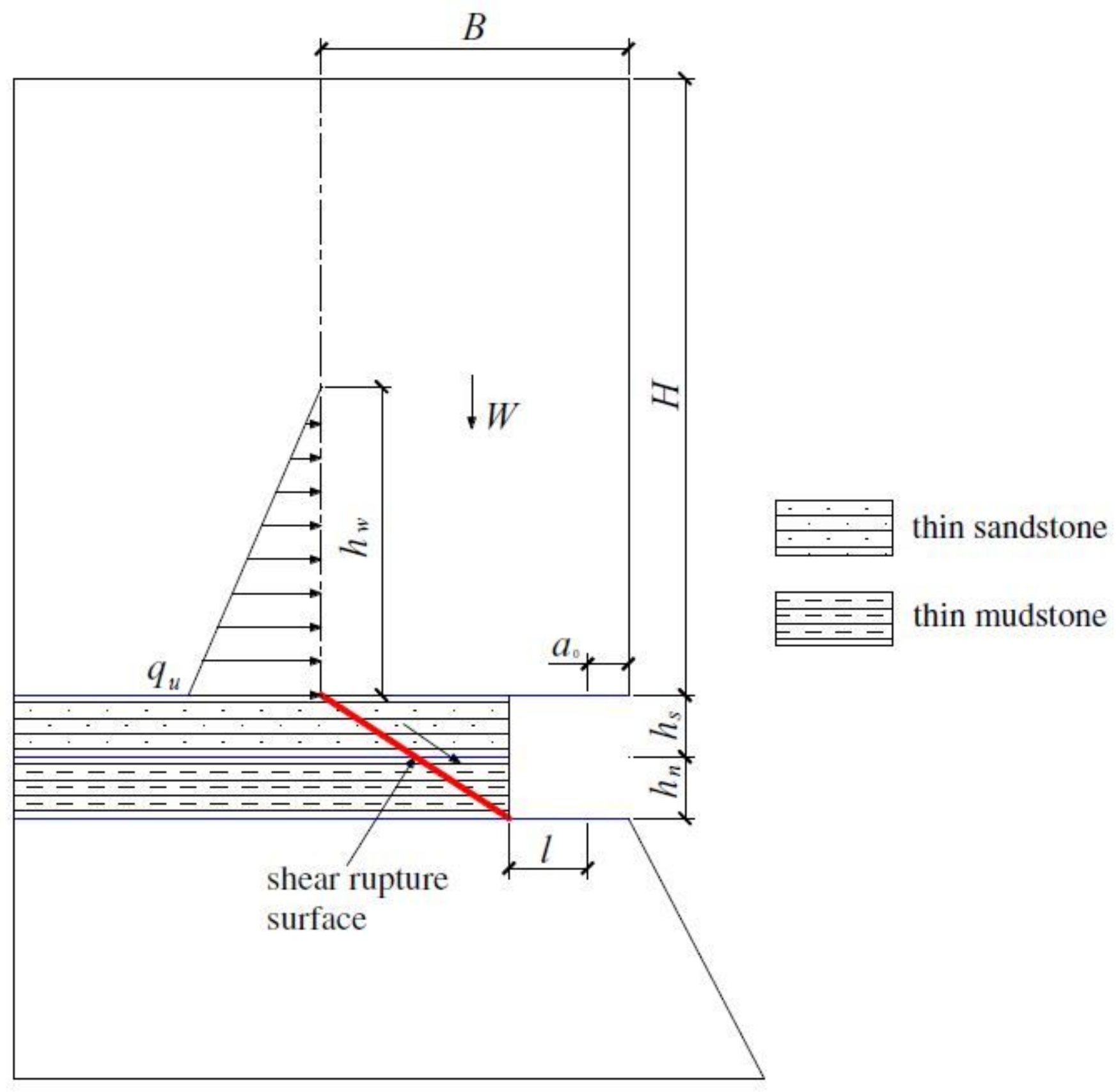

Figure 5

Failure mode of slip-shear 


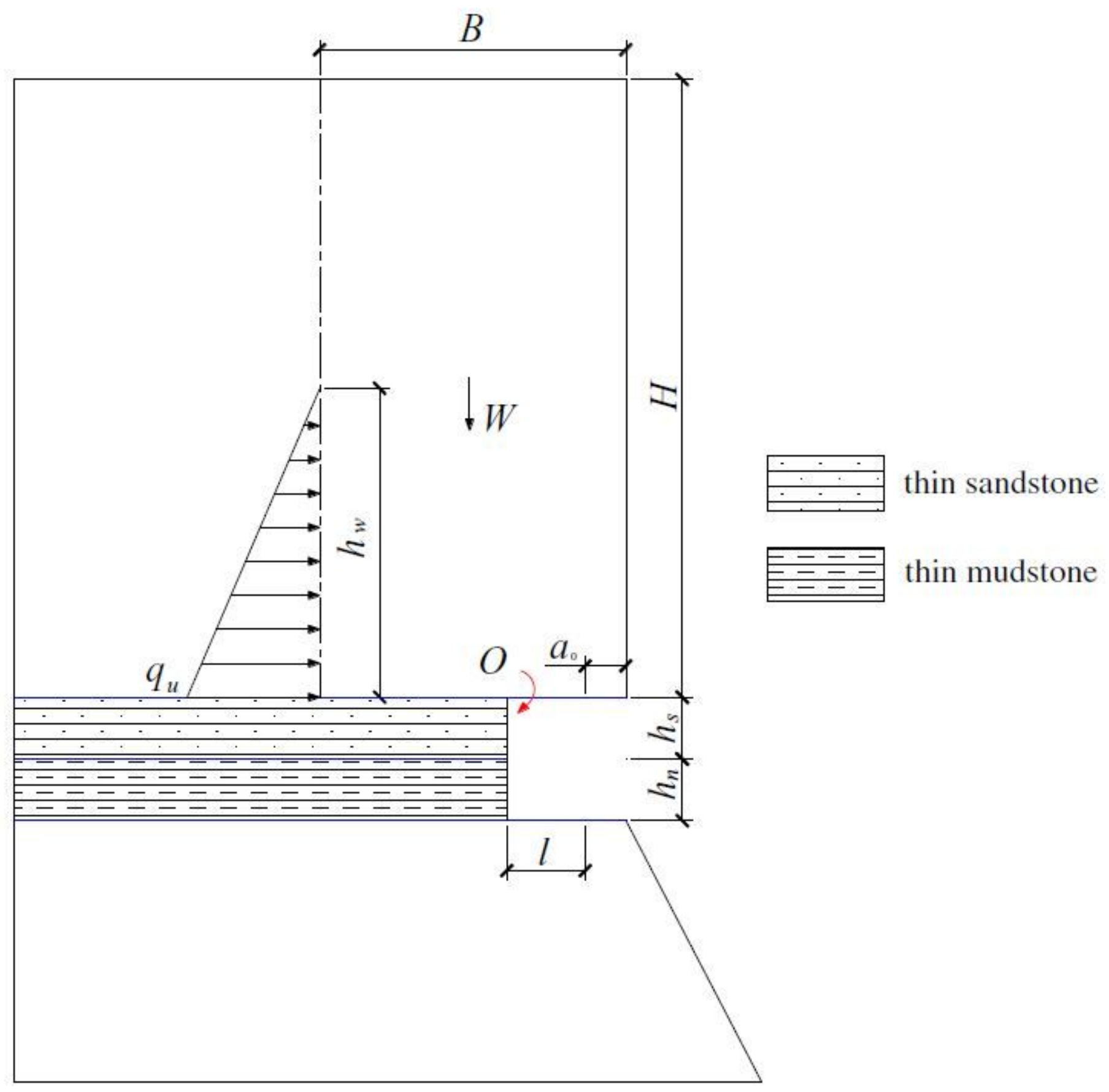

Figure 6

Failure mode of toppling-fall 


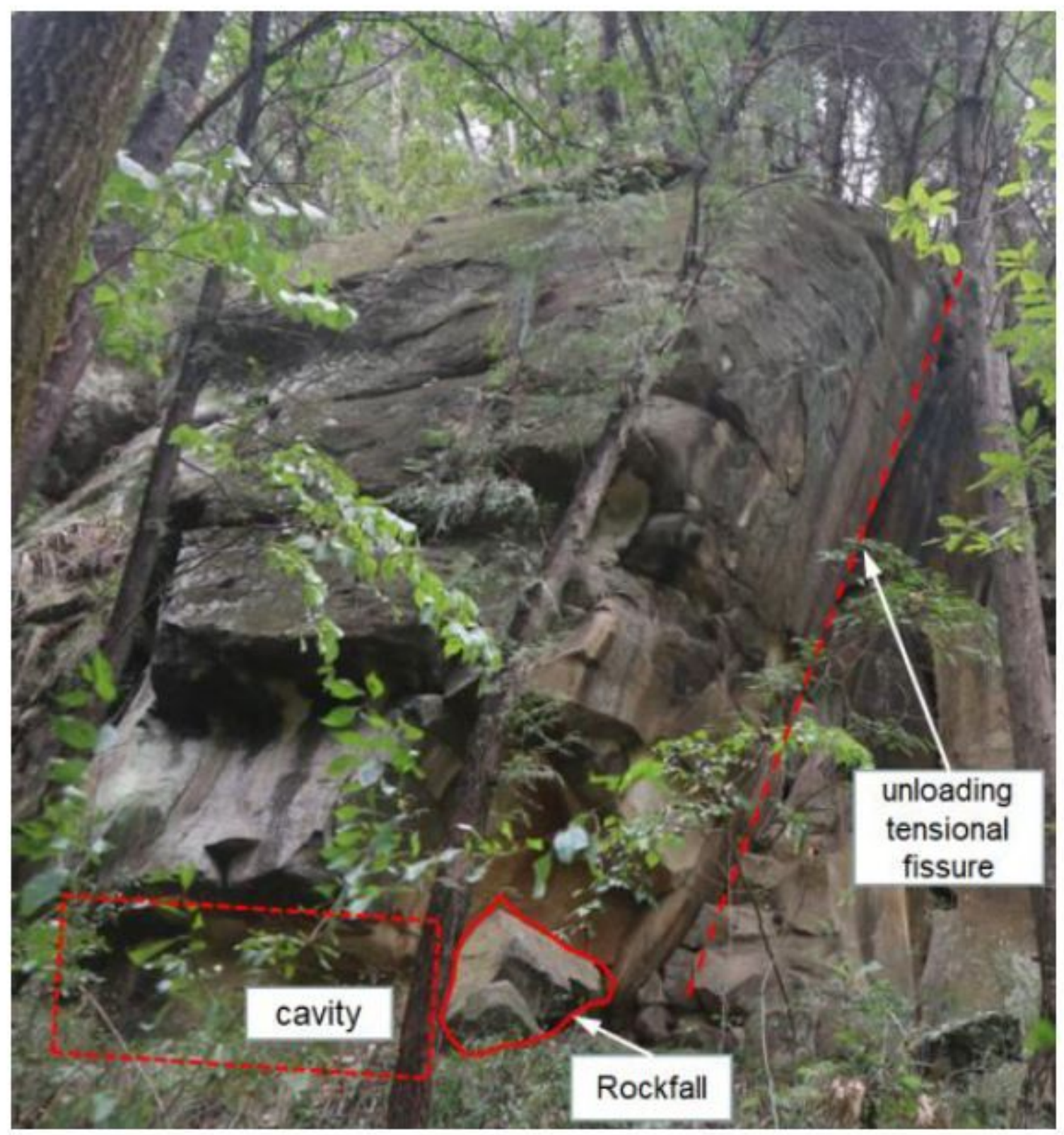

Figure 7

Full view of Leijiagou Perilous Rock 


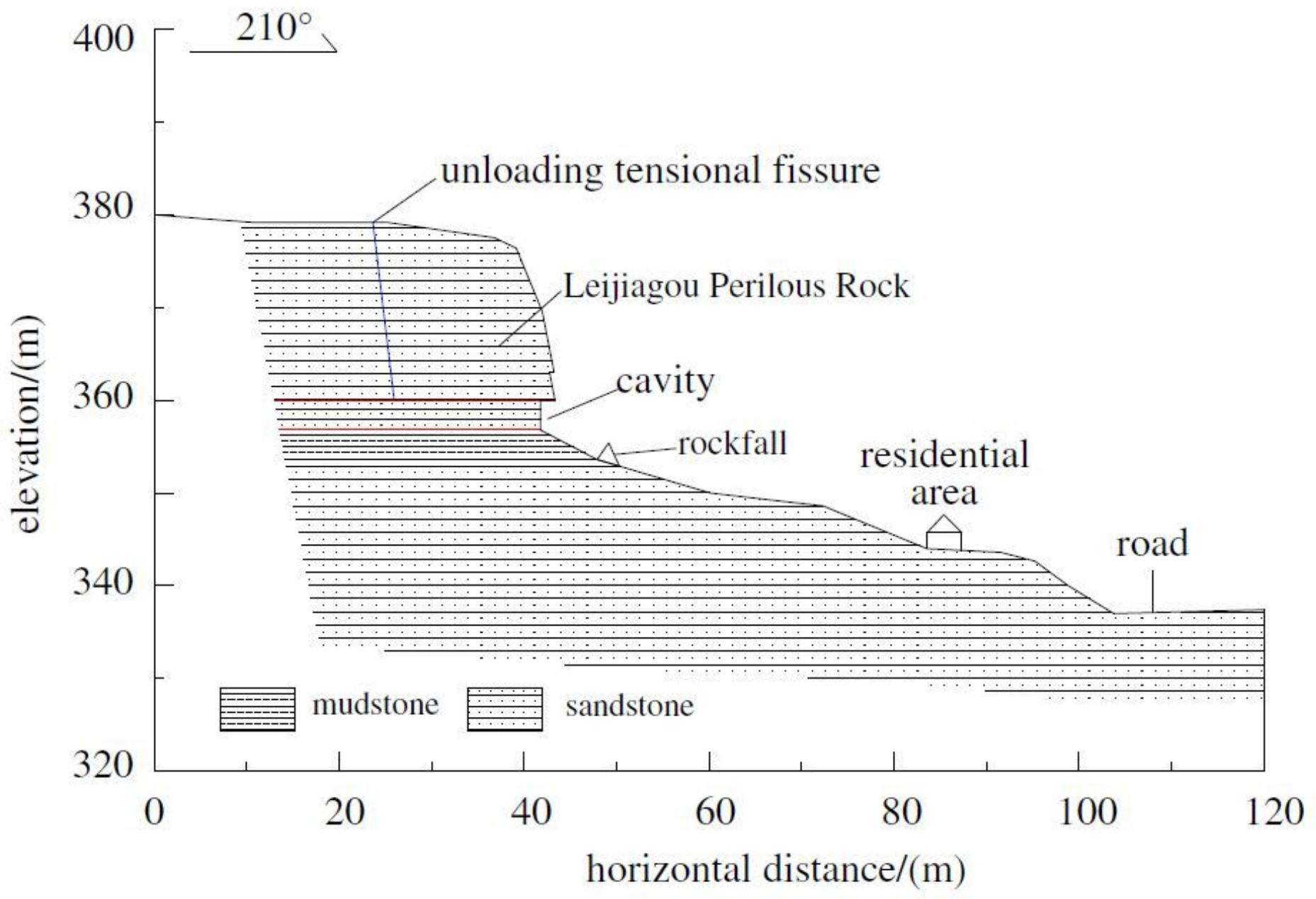

Figure 8

Engineering geologic profile of Leijiagou Perilous Rock 


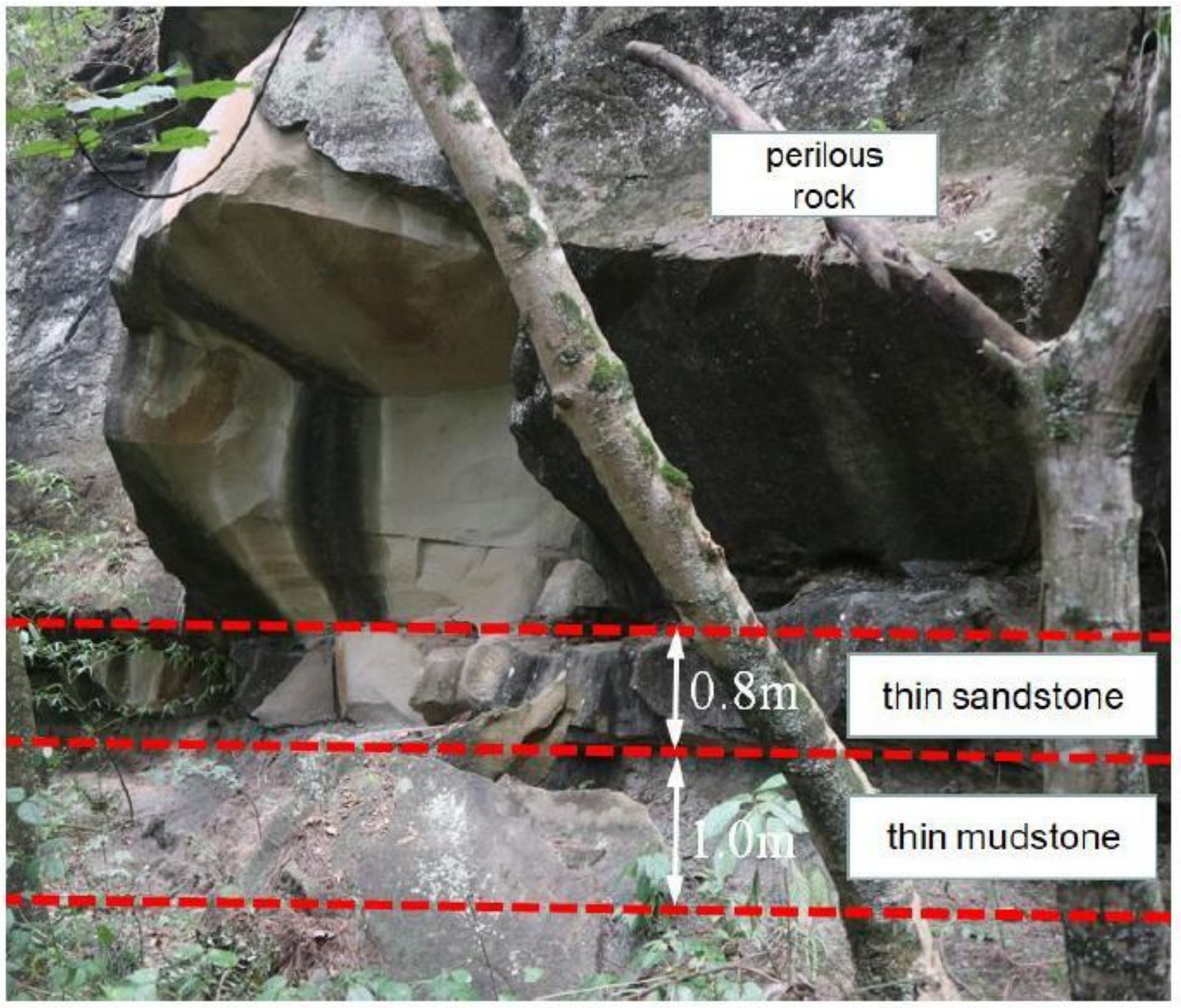

Figure 9

Foundation beds of Leijiagou Perilous Rock 